\title{
Alpha Glucuronidase Measurement
}

National Cancer Institute

\section{Source}

National Cancer Institute. Alpha Glucuronidase Measurement. NCI Thesaurus. Code C80165.

The determination of the amount of alpha glucuronidase present in a sample. 